|| ISSN(online): 2589-8698 || ISSN(print): 2589-868X ||

International Journal of Medical and Biomedical Studies

Available Online at www.ijmbs.info

NLM (National Library of Medicine ID: 101738825)

Index Copernicus Value 2019: 79.34

Original Research Article

Volume 5, Issue 8; August: 2021; Page No. 345-347

\title{
PERINATAL OUTCOME OF SECOND BORN TWIN
}

\section{Dr Hemant Singh Shekhawat ${ }^{1}$, Dr Ritu Gupta ${ }^{2}$}

${ }^{1}$ Resident Doctor, Department of Obstetrics and Gynaecology, Jhalawar Medical College, Jhalawar

${ }^{2}$ Senior Professor and Unit Head, Department of Obstetrics and Gynaecology, Jhalawar Medical College, Jhalawar

Article Info: Received 14 June 2021; Accepted 28 August 2021

DOI: https://doi.org/10.32553/ijmbs.v5i8.2158

Corresponding author: Dr Hemant Singh Shekhawat

Conflict of interest: No conflict of interest.

\section{Abstract}

Background: The second twin is generally considered at higher risk of severe morbidity and mortality because of obstetric complications that may occur after delivery of the first twin.

Methods: The hospital based descriptive type of observational study was conducted in the Department of Obstetrics and Gynaecology, Jhalawar Medical College, Jhalawar.

Results: In 54.00\% neonate APGAR score was 5-7 followed by $42.00 \%$ neonate APGAR score was $>7$ and $4.00 \%$ neonate APGAR score was less than $5.84 .00 \%$ delivery were ND followed by $14.00 \%$ delivery was AVBD and $2.00 \%$ delivery was IPV-BE.

Conclusion: Second twin had low Apgar score and chance of neonatal admission was more.

Keywords: NICU, APGAR score, Neonates.

\section{Introduction}

A multiple birth is a birth of two or more babies in one parturition. Simultaneous development of two fetus (twin) is the commonest, although with newer infertility treatment protocols, development of 3-8 fetus have been reported. ${ }^{1}$

Twin pregnancies have been found to vary in different parts of the world. The highest incidence is in Nigeria (49/1000) and the lowest in China and Japan (2/1000) while Europe and USA have the intermediate incidence (5.9-8.9/1000). The incidence of twin pregnancy has been on the rising trend, $65 \%$ since $1980 .^{2}$

The second twin is generally considered at higher risk of severe morbidity and mortality because of obstetric complications that may occur after delivery of the first twin. Including placental separation, cord prolapse, uterine atony, long interval delivery and cervical spasm. ${ }^{3}$

\section{Material \& Methods}

\section{Study Design:}

Hospital-based descriptive type of observational study.

\section{Type of Study:}

Descriptive type

\section{Study Population:}

Pregnant women who have confirmed diagnosis of twin gestation attending Labour room of Department of Obstetrics and Gynaecology, Jhalawar Medical College \& Associated Hospitals with period of gestation 28 weeks or more was included in the study.

\section{Inclusion Criteria}

- Diagnosis of twin pregnancy confirmed by ultrasound examination.

- Pregnant women who have twin gestation with period of gestation 28 weeks or more and are giving written and inform consent.

- Age between 18-36 years.

- First twin with cephalic presentation and selected for vaginal delivery.

\section{Exclusion Criteria}

- Pregnant woman with pre-existing medical complication like chronic hypertension, diabetes mellitus, renal disease, collagen vascular disease, or any other disorder that could complicate the present pregnancy.

- Intrauterine death of either one of twin before the onset of labour.

- Pregnancies complicated by fetal malformation or lethal anomaly of either twin.

- Contraindication to vaginal delivery.

\section{Methodology}

- After their complete medical \& surgical history and a thorough physical examination was done.

- After applying inclusion and exclusion criteria patients written informed consent was taken. 
- All the relevant information were recorded in the case record form, e.g., maternal age, gravidity, parity, detailed history, clinical examination findings including obstetric examination, ultrasound reports, gestational age at birth, presentation of both the fetuses at labor and delivery, mode of delivery, birth weight, and lastly, perinatal outcome of the babies including perinatal morbidity (neonatal illness and complications), and mortality (stillbirth and early neonatal death).

\section{Statistical Analysis}

Continuous variables were summarised as Mean and Standard Deviation whereas nominal / categorical variables as proportion (\%). Unpaired ' $t$ ' test and parametric test were used for analysis of continuous variables while chi-square test / fisher exact test and other non-parametric test was used for normal / categorical variables. p-value $<0.05$ was taken as significant.

\section{Observations}

Table 1: Birth weight wise distribution

\begin{tabular}{|l|l|}
\hline Mean birth weight (Kg) & 1.92 \\
\hline SD & 0.68 \\
\hline
\end{tabular}

Maximum newborn 22 (44\%) were in range $2.1-2.5 \mathrm{~kg}$. Mean birth weight was $1.86 \pm 0.62 \mathrm{Kg}$.

Table 2: APGAR score wise distribution

\begin{tabular}{|l|l|l|}
\hline APGAR score at 5 min. & No. of cases & Percentage \\
\hline Less than 5 & 2 & $4.00 \%$ \\
\hline $\mathbf{5 - 7}$ & 27 & $54.00 \%$ \\
\hline$>7$ & 21 & $42.00 \%$ \\
\hline Total & $\mathbf{5 0}$ & $\mathbf{1 0 0 . 0 0} \%$ \\
\hline
\end{tabular}

In 54.00\% neonate APGAR score was 5-7 followed by $42.00 \%$ neonate APGAR score was $>7$ and $4.00 \%$ neonate APGAR score was less than 5.

Table 3: NICU admission wise distribution

\begin{tabular}{|l|l|l|}
\hline NICU admission & No. of cases & Percentage \\
\hline Yes & 16 & $32.00 \%$ \\
\hline No & 34 & $68.00 \%$ \\
\hline Total & $\mathbf{5 0}$ & $\mathbf{1 0 0 . 0 0 \%}$ \\
\hline
\end{tabular}

In our study $32.00 \%$ neonates were admitted in NICU. There lower birth weight \& prematurity had higher morbidities and mortalities

Table 4: Neonatal mortality wise distribution

\begin{tabular}{|l|l|l|}
\hline Neonatal mortality & No. of cases & Percentage \\
\hline Yes & 4 & $8.00 \%$ \\
\hline No & 46 & $92.00 \%$ \\
\hline Total & $\mathbf{5 0}$ & $\mathbf{1 0 0 . 0 0 \%}$ \\
\hline
\end{tabular}

Prevalence of neonatal mortality in our study was $8.00 \%$.

Table no. 5. Mode of delivery wise distribution

\begin{tabular}{|l|l|l|}
\hline Mode of delivery & No. of cases & Percentage \\
\hline AVBD & 7 & $14.00 \%$ \\
\hline ND & 42 & $84.00 \%$ \\
\hline IPV-BE & 1 & $2.00 \%$ \\
\hline Total & $\mathbf{5 0}$ & $\mathbf{1 0 0 . 0 0 \%}$ \\
\hline
\end{tabular}

In our study was $84.00 \%$ delivery were ND followed by $14.00 \%$ delivery was AVBD and $2.00 \%$ delivery was IPV-BE.

\section{Discussion}

Maximum newborn $22(44 \%)$ were in range $2.1-2.5 \mathrm{~kg}$. Mean birth weight was $1.86 \pm 0.62 \mathrm{Kg}$.

Twin pregnancy is more likely to be characterized by LBW than singleton pregnancy mostly due to fetal growth restriction and preterm delivery ${ }^{4}$. The percentages of VLBW
$(<1500 \mathrm{~g})$ and LBW $(1500-<2500 \mathrm{~g})$ babies were higher among the second twins compared to the first twins. We also observed that perinatal outcome of the second twins was unfavorable among LBW $(<2500 \mathrm{~g})$ babies than normal birth weight $(\geq 2500 \mathrm{~g})$ babies. Other studies also support our findings ${ }^{5,6}$. 
In $54.00 \%$ neonate APGAR score was 5-7 followed by $42.00 \%$ neonate APGAR score was $>7$ and $4.00 \%$ neonate APGAR score was less than 5. Which could be due to the reason that preterm babies are more easily affected by asphyxia than their term counterparts. Similar to this study, Armson et $\mathrm{al}^{7}$ also observed lower APGAR scores in premature neonates which they have attributed to the lower gestational age and low birth weight

In this study, low APGAR score in the second twins was comparable to the similar study done by Hartley and Hitti, ${ }^{8}$ and Chang et al. ${ }^{9}$ This could be due to reduced placental circulation after the delivery of the first twin and potentially greater susceptibility of second twin to hypoxia. Yang et al ${ }^{10}$ also observed low APGAR score for second twin.

In our study $32.00 \%$ neonates were admitted in NICU. There lower birth weight \& prematurity had higher morbidities and mortalities. Joshi $\mathrm{R}$ et $\mathrm{al}^{11}$ observed that $30.00 \%$ neonates admitted in NICU

Prevalence of neonatal mortality in our study was $8.00 \%$.

Katarzyna Kosińska-Kaczyńska et $\mathrm{al}^{12}$ was observed that prevalence of neonatal mortality in our study were $4.3 \%$.

\section{Conclusion}

Second twin had low Apgar score and chance of neonatal admission was more.

\section{Bibliography}

1. ACOG. Multiple gestation: complicated twin, triplet, and high order multifetal pregnancy. Practice bulletin No. 56. Obstet Gynaecol. 2004; 104(4): 869-83.

2. Multiple pregnancy. In: Cunningham FG, Levono KJ, Bloom SL, Hauth JC, Rouse DJ, Spong YC, editors. Williams Obstetrics. $23^{\text {rd }}$ ed. New York: Mc GrawHill ; 2010. p. 859-89.
3. MacKay AP, Berg CJ, King JC, Duran C, Chang J. Pregnancy related mortality among women with multifetal pregnancies. ObstetGynecol2006; 107: 563-8.

4. Buekens P,Wilcox A. Why do small twins have a lower mortality rate than small singletons?Am J Obstet Gynecol.1993;168:937-41.

5. Aisien AO, Olarewaju RS, Imade GE. Twins in Jos Nigeria: a seven-year retrospective study. Med Sci Monit. 2000;6:945-50.

6. Donovan EF, Ehrenkrantz RA, Shankaran S, et al. Outcomes of very low birth weight twins cared for in the National Institute of Child Health and Human Development Neonatal Research Network's intensive care units. Am J Obstet Gynecol. 1998;179: 742-9.

7. Armson BA, O'Connell C, Persad V, Joseph KS, Young DC, Baskett TF. Determinants of perinatal mortality and serious neonatal morbidity in the second twin. Obstet Gynecol. 2006;108(3):556-64.

8. Hartley RS, Hitti J. Birth order and delivery interval: analysis of twin pair perinatal outcomes. J Matern Fetal Neonatal Med. 2005;17(6):375-80.

9. Chang TH, Jeng CJ, Lan CC. The effect of birth order in twins on fetal umbilical blood gas and Apgar score. Zhonghua Yi XueZaZhi. 1990;46(3):156-60.

10. Yang Q, Wen SW, Chen Y, Krewski D, Fung Kee Fung $\mathrm{K}$, Walker M. Neonatal mortality and morbidity in vertex-vertex second twins according to mode of delivery and birth weight. J Perinatol. 2006;26:3-10. doi: 10.1038/sj.jp.7211408.

11. Joshi R, Baral G. Perinatal Outcome of the Second Twin. NJOG 2015 Jan-Jun; 19 (1):89-93.

12. Katarzyna Kosińska-Kaczyńska, Iwona Szymusik. Perinatal outcome according to chorionicity in twins a Polish multicenter study. Ginekologia Polska 2016; 87, 5: 384-389. 